\title{
Optimal management of constipation associated with irritable bowel syndrome
}

\author{
This article was published in the following Dove Press journal: \\ Therapeutics and Clinical Risk Management \\ 30 April 2015 \\ Number of times this article has been viewed
}

\author{
Manuele Furnari' \\ Nicola de Bortoli ${ }^{2}$ \\ Irene Martinucci² \\ Giorgia Bodini' \\ Matteo Revelli ${ }^{3}$ \\ Elisa Marabotto' \\ Alessandro Moscatelli' \\ Lorenzo Del Nero' \\ Edoardo Savarino ${ }^{4}$ \\ Edoardo G Giannini' \\ Vincenzo Savarino' \\ 'Division of Gastroenterology, \\ Department of Internal Medicine, \\ University of Genoa, Genoa, Italy; \\ 2Division of Gastroenterology, \\ Department of Translational Research \\ and New Technology in Medicine \\ and Surgery, University of Pisa, Pisa, \\ Italy; ${ }^{3}$ Department of Radiology, \\ San Bartolomeo Hospital, Sarzana, \\ Italy; ${ }^{4}$ Division of Gastroenterology, \\ Department of Surgery, Oncology, \\ and Gastroenterology, University \\ of Padua, Padua, Italy
}

\begin{abstract}
Irritable bowel syndrome (IBS) is a common chronic functional disorder of the gastrointestinal tract, meanly characterized by recurrent abdominal pain or discomfort and altered bowel habit. It is a complex disorder involving biological, environmental, and psychosocial factors. The diagnosis is achieved according to the Rome III criteria provided that organic causes have been excluded. Although IBS does not constitute a life-threatening condition, it has a remarkable prevalence and profoundly reduces the quality of life with burdening socioeconomic costs. One of the principal concerns about IBS is the lack of effective therapeutic options. Up to $40 \%$ of patients are not satisfied with any available medications, especially those suffering from chronic constipation. A correct management of IBS with constipation should evolve through a global approach focused on the patient, starting with careful history taking in order to assess the presence of organic diseases that might trigger the disorder. Therefore, the second step is to examine lifestyle, dietary habits, and psychological status. On these bases, a step-up management of disease is recommended: from fiber and bulking agents, to osmotic laxative drugs, to new molecules like lubiprostone and linaclotide. Although new promising tools for relief of bowel-movement-related symptoms are being discovered, a dedicated doctor-patient relationship still seems to be the key for success.
\end{abstract}

Keywords: IBS, functional gastrointestinal disorders, laxatives

\section{Introduction}

Irritable bowel syndrome (IBS) is a common chronic functional disorder of the gastrointestinal tract, meanly characterized by recurrent abdominal pain or discomfort and altered bowel habit. ${ }^{1}$ The diagnosis is achieved according to the Rome III criteria provided that organic causes have been excluded. ${ }^{2}$ Abdominal discomfort should be at least 3 days per month in the last 3 months and associated with change either in frequency or form of stool and/or improved with defecation. ${ }^{3}$ The overall prevalence in European countries ranges from $6 \%$ to $12 \%$ with the peak among middle-aged women, but it varies according to the geographic area considered. ${ }^{4}$ The pathophysiology of IBS is still subject of intense research and several factors seem to be involved: visceral hypersensitivity, psychosocial dysfunction, gastrointestinal motility, postinfectious development, impaired intestinal microbiota, food sensitivity, intestinal inflammation, and genetic factors. ${ }^{5-8}$ Although clinical manifestations are not specific and overlap with many other diseases, IBS may fall into three different variants: ${ }^{9,10}$

- IBS with constipation (IBS-C); hard/lumpy stools predominant over normal/loose stools.

- IBS with diarrhea; watery/loose stools predominant over normal/lumpy stools.

- Mixed IBS; both hard and watery stools represent $\geq 25 \%$ of bowel movements.

A forth variant, named unsubtyped IBS due to insufficient abnormalities in stool, may be further identified. It must be acknowledge that these classes are inclined to
Correspondence: Manuele Furnari

Division of Gastroenterology,

Department of Internal Medicine,

University of Genoa, Viale Benedetto XV,

6, 16132 Genoa, Italy

Tel +39010 3538956

Fax +39010 3538956

Email manuele.furnari@unige.it
Therapeutics and Clinical Risk Management 2015:II 69I-703 LY License. The full terms of the license are available at http://creativecommons.org/licenses/by-n/3.0/. Non-commercial uses of the work are permitted without any further (c) (i) (5) 2015 Furnari et al. This work is published by Dove Medical Press Limited, and licensed under Creative Commons Attribution - Non Commercial (unported, v3.0) pers limited, provided the work is properly attributed. Permissions beyond the scope of the License are administered by Dove Medical Press Limited. Information on how to request permission may be found at: http://www.dovepress.com/permissions.php 
vary over time and patients may repeatedly switch from one form to another. ${ }^{11}$

Although IBS does not constitute a life-threatening condition and there is not impact on life expectancy, it profoundly reduces the quality of life with burdening socioeconomic costs. ${ }^{12-14}$ These latter costs consist of increased utilization of health care resources (ie, frequent visits to physicians, long-term medications use, redundant invasive expensive investigations) and reduced work productivity (ie, absenteeism and presenteeism).

One of the principal concerns about IBS is the lack of effective therapeutic options. A considerable proportion of patients are not satisfied with any available medications (up to $40 \%$ ), ${ }^{15,16}$ especially those suffering from chronic constipation. ${ }^{17}$ Although new promising tools for relief of bowel-movement-related symptoms are being discovered, a dedicated doctor-patient relationship seems to be the key for success. ${ }^{18-22}$

Therefore, a narrative review of the pathophysiologic factors and therapeutic options of IBS associated with constipation is important. The aim of this work is to provide an overview of knowledge that is detailed and up to date to the clinicians to allow for better awareness and management of IBS-C.

\section{Pathophysiology mechanism}

IBS is a complex and heterogeneous disorder whose pathophysiological mechanisms are poorly understood. Nevertheless, previous studies have proposed that motility dysfunctions, visceral hypersensitivity, and brain-gut interplays can represent the main pathophysiological mechanisms of IBS. ${ }^{23,24}$ Evidence supports the hypothesis that IBS etiology is multifactorial in nature involving biological, environmental, and psychosocial factors. In particular, recent genetic studies have defined IBS as a "complex genetic disorder" resulting from a combination of multiple genetic variants (ie, several genes encoding proteins/peptides related to gastrointestinal function) and environmental factors (ie, diet, infections, stressful events). ${ }^{25,26}$ In the recent review by Saito, the estimated genetic liability and heritability in IBS, based on twin studies, ranged between $1 \%$ and $20 \%$ and between $0 \%$ and $57 \%$, respectively. Moreover, the same author reported more than 60 genes as potentially involved in IBS pathogenesis and grouped them into subclasses according to the pathway in which they are involved (ie, serotonergic, adrenergic, inflammatory, or intestinal barrier genes). ${ }^{25}$ However, to date, there is no conclusive evidence regarding a concrete genetic basis able to determine IBS or its phenotype, and confirmation with genome-wide association studies in IBS is still required..$^{27,28}$

With regard for gastrointestinal dysmotility, the American Gastroenterological Association technical review underlined the lack of consensus on the patterns of motility responsible for constipation and diarrhea in IBS, although delayed colonic transit was seen in constipation and accelerated transit in diarrhea. ${ }^{29}$ It is worth noting that motility abnormalities may interact with low sensory thresholds to produce symptoms. Indeed, Serra et $\mathrm{al}^{30}$ suggested that delayed transit of gas causes greater abdominal perception in patients with IBS. More recently, Prott et $\mathrm{al}^{31}$ demonstrated new relationships between certain pelvic floor dyssynergia symptoms and disordered anorectal physiology in patients with non-diarrhea predominant IBS, thus emphasizing that these patients with non-diarrhea predominant IBS may have pelvic floor dysfunction despite the fact that these two conditions are mutually exclusive by Rome criteria. Moreover, this study also showed that non-diarrhea predominant IBS patients with a physiological diagnosis of pelvic floor dysfunction were more likely to exhibit hypersensitivity to pain. ${ }^{31}$

The role of visceral hypersensitivity to a variety of stimuli (eg, balloon distension, electrical stimulation) has been extensively investigated within the setting of IBS, implicating that IBS patients display a reduced threshold to pain or discomfort in response to visceral stimulation, as compared to normal subjects. ${ }^{32-34}$ Several lines of evidence are consistent with the notion that visceral hypersensitivity is not site-specific and can be usually documented throughout the whole gastrointestinal tract, suggesting a diffuse involvement in IBS patients. ${ }^{35-38}$ Nevertheless, the mechanisms underlying this enhanced visceral sensitivity, likely involving altered peripheral/central processing of sensory input and psychoneuroimmune interactions, have not been fully elucidated. ${ }^{39-41}$ Particularly, it remains unclear what psychological factors are relevant for visceral hypersensitivity in IBS patients, and how they may interact with biological mechanisms, such as peripheral/central neuro-endocrine and immune processes. ${ }^{42}$ Presence of anxiety and depression, history of sexual abuses, family loss, and insufficient coping strategies are just some of the factors that should be evaluated carefully. Currently, a growing interest has been focused on the complex interplay between the central, enteric, and autonomic nervous system, named the brain-gut axis. Indeed, a continuous bidirectional interplay between the gut and the brain occurs via neural, immunological, and hormonal routes, and, once altered, plays a pivotal role in functional gastrointestinal disorders, allowing transmission of emotional states from the central 
nervous system to the gut, and perception of gastrointestinal changes (pain, contractions, bloating) to the central nervous system. ${ }^{43,44}$ Based on the assumption that IBS has a variety of environmental risk factors, ${ }^{45}$ they can all influence the braingut axis, leading to abnormal gastrointestinal function and motility. Of note, recent evidence highlighted that alterations in gut barrier function/permeability, occurring in response, or in parallel, to changes in the intestinal microbiota, can determine aberrant host immune responses and thus may contribute to the IBS pathogenesis. ${ }^{46}$ This field represents nowadays one of the most promising and revolutionary aspects of medicine. However, its discussion is beyond the purpose of this review and would be worth considering for a self-standing dissertation.

\section{Diagnosis}

IBS is commonly identified by symptom-based approaches and, according to the Rome III criteria, the main feature of IBS is the presence of recurrent abdominal pain or discomfort that is associated with defecation and/or a change in bowel habit. ${ }^{47}$ With regard to IBS-C, the stool pattern is characterized by the presence of hard or lumpy stools ( $\geq 25 \%$ of bowel movements) and loose or watery stools $(<25 \%$ of bowel movements). ${ }^{47}$

It is worth noting that the clinical definition of IBS has been subjected to changes over the years, from the Manning criteria in 1978 to three consecutive iterations of the Rome criteria, with the most recent one (Rome III) in 2006. However, no significant differences in sensitivity among these various symptom-based criteria have been demonstrated. ${ }^{48,49}$ Of note, the recent cross-sectional study by Engsbro et $\mathrm{al}^{49}$ supported the relevance of the Rome III criteria for IBS in primary care, identifying a subpopulation of patients with qualitatively different symptoms, a higher symptom burden, and a lower health-related quality of life compared with patients not fulfilling such criteria.

Considering that IBS diagnosis consists of symptombased criteria, the role of a careful medical history is crucial, comprising all patient comorbidities and home therapies, which may influence the change of bowel habits. ${ }^{50}$ Moreover, psychological status and potential trauma, such as family loss, sexual abuse, and unemployment, should be ruled out. Patients are asked for an accurate symptom description regarding: whether there is pain relief with evacuation; the eventual negative influence of stressful events on frequency and severity of pain presentation; the relation of pain to food intake; and, for women, menstrual cycle. ${ }^{51}$ With regard to IBS-C, patients refer to difficulty in passing hard/lumpy stool (ie, straining defecation, need for manual help), infrequent bowel movements (three or less bowel movements per week), and/or a sense of incomplete evacuation. ${ }^{52}$ In clinical practice, the Bristol scale represents a useful guide for the description of stool consistency and shape. ${ }^{52}$ In addition to identifying the presence of the above clinical presentation, the symptom rate is important to fulfill the diagnostic criteria, which require their occurrence on at least 3 days per month in the last 3 months to indicate current activity, and at least 6 months before the patient presents to substantiate that IBS is a chronic disorder. ${ }^{47}$ Furthermore, the absence of alarm signs and symptoms (including new onset of symptoms in those $\geq 50$ years of age, unintentional weight loss, signs of gastrointestinal bleeding, nocturnal symptoms, family history of gastrointestinal diseases) is mandatory to confidently suppose the diagnosis of a functional disease such as IBS..$^{53-55}$

According to the American College of Gastroenterology Task Force on IBS, clinical investigations to exclude organic cause are not recommended in patients who meet the IBS Rome III criteria and lack any alarm features. ${ }^{3}$ In the setting of IBS-C, patients with severe and/or refractory constipation may undergo a more accurate diagnostic workup including colonic transit time, anorectal manometry, and defecography. ${ }^{56}$

Current evidences point out a significant degree of overlap between IBS and other functional gastrointestinal disorders, ${ }^{57}$ with various upper and lower gastrointestinal tract symptoms that may occur in the same patients and fluctuate over time. ${ }^{58}$ Thus, the possibility to distinguish these entities is somewhat of a challenge for gastroenterologists. In this context, Wong et $\mathrm{al}^{59}$ showed that patients identified by the Rome III criteria for functional constipation and IBS-C share bowel and abdominal symptoms, as well as most of the available drug therapies. Thus making it difficult to clearly discriminate the two disorders. Shekhar et $\mathrm{al}^{60}$ highlighted that patients with IBS-C or functional constipation had similar baseline symptoms, bowel habits, orocecal and colonic transit, and fasting concentrations of serotonin. However, only patients with IBS-C had an increase in abdominal symptoms after meal ingestion. Of note, this study showed that increased platelet-depleted plasma 5-HT concentration was associated with reduced visceral sensitivity and stool frequency both in patients with functional constipation and IBS-C ${ }^{60}$ More recently, the results of a community survey by Rey et $\mathrm{al}^{61}$ concluded that functional constipation is supposed to be a spectrum, in which most patients do not have abdominal pain but other patients have IBS or are out of any currently 
established diagnosis. A previous study from our group showed a higher concentration and excretion rate of methane $\left(\mathrm{CH}_{4}\right)$ in breath samples among functional constipation compared to IBS-C, thus supposing that different mechanisms are involved in their genesis. ${ }^{62}$ However, it must be pointed out that the wide overlap existing between the two groups does not allow us to use the Breath Test as a reliable diagnostic tool to discriminate them. Similarly, it cannot discriminate them from prolonged OCTT due to organic diseases (ie, systemic sclerosis). ${ }^{63}$ Overall, on the basis of current and future epidemiological and pathophysiological studies, the Rome III criteria will likely continue to evolve to provide the most appropriate characterization of patients with functional bowel symptoms. ${ }^{64} \mathrm{~A}$ flow chart summarizing the mean diagnostic process for IBS-C patients is depicted in Figure 1.

\section{Role of radiologic investigations}

The matter of radiologic imaging impact in diagnosis and management of patients with IBS has already been widely discussed in literature, especially considering those cases

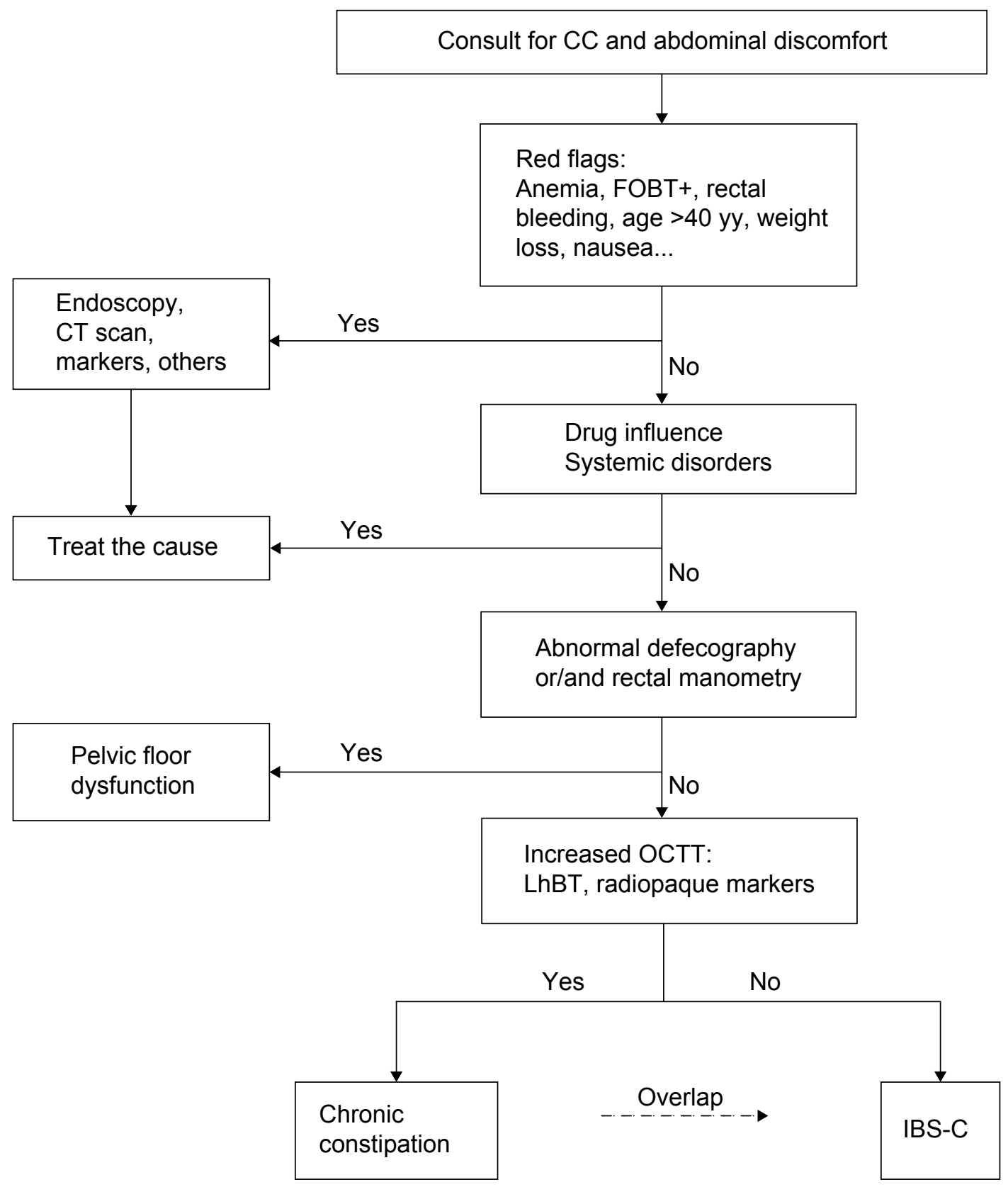

Figure I Diagnostic flowchart of patients referring to specialists for chronic constipation and abdominal discomfort.

Abbreviations: CC, chronic constipation; CT, computed tomography; FOBT+, fecal occult blood test positive; IBS-C, irritable bowel syndrome constipation variant; LhBT, Lactulose breath test; OCTT, orocecal transit time. 
in which symptoms can be the expression of an underlying disease with specific structural modifications; ${ }^{65}$ however, it is particularly important to highlight that the presence of such alterations does not necessarily exclude the diagnosis of IBS, and it could help physicians to address their attention to the choice of the most suitable imaging modality, considering the most likely differential diagnoses and the most typical symptoms. Guidelines based on systematic reviews may prescribe the use of bowel imaging, abdominal ultrasound (US), and computed tomography (CT) in IBS, suggesting that these modalities should address the most likely underlying disease. ${ }^{66}$ The clearest example of the role played by diagnostic imaging is represented by pelvic or abdominal US performed in patients reporting abdominal pain with biliary features and rise of liver enzymes, since the overlap between IBS and gall stones is a well-known entity. ${ }^{67}$ However, physicians should be prudent in the evaluation of gallbladder US findings in IBS, and radiological assessment should be limited to patients with typical meal-provoked symptoms. Little attention in literature has been paid regarding the application of barium enema or CT colonography in IBS; the American College of Gastroenterology guidelines suggest that patients with IBS requiring further investigations should undergo colonoscopy rather than barium enema or CT colonography, because of their inability to perform random biopsies. However, in patients with IBS-C, no colonic examinations are suggested over others (conventional colonoscopy, CT colonography, barium enema) to investigate causes of mechanical obstruction. ${ }^{68}$ Other radiological approaches to IBS are represented by calculation of colonic transit time by use of radiopaque markers, defecography (or more recently magnetic resonance defecography), ${ }^{69}$ and quantitative analysis of bowel gas using plain abdominal radiograph. ${ }^{70}$ In particular, the evaluation of bowel transit alterations in IBS has been proposed, although its value is not completely clear; the use of radiopaque markers may provide important information about dysmotility and about accelerated or delayed transit time but no correlations of clinical significance have ever been found between transit data and specific gastrointestinal symptoms. ${ }^{71,72}$ The study of colonic transit based on ingested radiopaque markers has been widely used and it can be useful in studying slow transit constipation, providing an evaluation of the progression time (monitored 24 hours and 5 days after administration of about 30 inert cylinders on plain abdominal X-rays) of the markers through the large intestine. A modification in the distribution of markers in the bowel may suggest a colonic dysmotility. As a consequence, the results of marker studies have a clinical impact in the management of patients with constipation-variant IBS. ${ }^{73}$ Very recently, the use of LhBT combined with abdominal MRI has shown promising results in extimating OCTT. ${ }^{74}$ Defecography is another interesting radiologic modality that can provide important information: it is a morphodynamic examination that evaluates the presence of rectum and pelvic floor disorders by documenting the act of defecation using semisolid barium through videofluorographic recording. ${ }^{75}$ In recent years, a novel modality called magnetic resonance defecography, consisting of defecography by magnetic resonance imaging, has been developed: it can allow a panoramic visualization of rectum and pelvic floor compartments, with dynamic images providing morphological and functional information with sparing of ionizing radiations. ${ }^{75}$ However, it is important to underline that in the last years these modalities have shown a limited impact on IBS, which still remains basically a clinical entity.

\section{Treatment}

In the last decade, the management of IBS was symptombased. Actually, the recent advance in the understanding of the complex interaction between gut, immune system, and nervous system (the so called gut-brain axis) has led to an increase in the therapeutic arsenal for relief of both bowelmovement-related symptoms and pain. ${ }^{76}$ Moreover, the evaluation of drug efficacy in IBS underwent major changes especially with regard to trial design and clinical endpoints, ${ }^{77}$ from a single endpoint to a so-called binary endpoint.

The USA Food and Drug Administration (FDA) recommended the focus on two of the most relevant aspects of IBS: abdominal pain and defecation disorder. ${ }^{78}$ In particular, in predominant IBS-C, responder definition includes a more than $30 \%$ reduction from baseline in the weekly mean of the daily scores for worst abdominal pain and an increase of more than one complete spontaneous bowel movement (CSBM) per week from baseline, both in the same week, for at least $50 \%$ of the treatment period weeks.

Also, the Europeans Medicines Agency (EMA) in January 2014 finalized a new guideline about medical products proposed for IBS treatment. Based on Rome III criteria, two coprimary endpoints - that is, abdominal pain and evaluation of stool frequency for IBS-C (based on the number of CSBMs per week) - were considered. This change allows easier comparison with the FDA endpoints. ${ }^{79}$ Using those restrictive binary endpoints, the prokinetic molecule prucalopride (ie, selective 5- $\mathrm{HT}_{4}$ receptor agonist), despite promising therapeutic effects without significant cardiovascular events to date, is not currently approved in the USA or Europe in IBS-C patients. ${ }^{80,81}$ 
Nowadays, lubiprostone and linaclotide are the prosecretory agents available in IBS-C with a significant difference from the placebo according to the new standard proposed by the FDA and EMA. Specifically, lubiprostone received approval only for a subgroup of patients with IBS (women $>18$ years old) ${ }^{82}$ whereas linaclotide is contraindicated by the FDA in pediatric patients up to 6 years of age and its administration should be avoided in pediatric patients 6-17 years of age. ${ }^{83,84}$ Several other agent with serotonergic action have been proposed for IBS with diarrhea. However, most of them have been withdrawn due to severe adverse events or their indication restricted to chronic constipation. Tegaserod is still available, with some exceptions, in women with severe IBS-C. A summary of serotonergic and prosecretory agents is presented in Table 1 .

However, to think that these innovative drugs are the final solution for patients suffering from IBS-C would be a mistake. Their efficacy is still under assessment and a dedicated doctor-patient relationship still seems to be the key for a successful treatment. Strength of the recommendations and quality of the evidences supporting the therapeutic options are summarized in Table 2 .

A correct management of IBS-C should be a global approach focused on the patient, starting with careful history taking in order to assess the presence of organic diseases that might trigger the disorder. Therefore, the second step is to examine lifestyle, dietary habits, and psychological status. On these bases, a step-up management of disease is recommended: from fiber and bulking agents, to osmotic laxative drugs, to new molecules like lubiprostone and linaclotide (Figure 2).

\section{Lifestyle and dietary changes}

During a first assessment, it is necessary to evaluate carefully dietary and lifestyle history, seeking for nutrition status, lack of physical activity, dietary fiber intake, and of suitable times for defecation. These are common problems which are involved in the development of IBS-C. ${ }^{85}$

As a consequence of first assessment, the initial treatment begins most of the time with lifestyle modifications, which include changes in fluids intake, exercise, and diet. Adequate hydration and fiber intake are considered by the majority of physicians to be key to beneficial clinical care and preventing problems, such as constipation, particularly in children and elderly. Regrettably, data to support these interventions are limited. In particular, even though the increase of dietary fiber and fluids intake is a standard recommendation for patients with IBS-C, its efficacy is controversial. ${ }^{86,87}$ Some studies suggested that principal sources of dietary fiber, such as bran, cereals, vegetables, and fruits, might actually exacerbated symptoms in IBS (ie, fructans, galacto-oligosaccharide, and sugar polyols). ${ }^{88}$

In this regard, in recent years, many studies have been conducted on the role of fermentable, oligo-, di-, monosaccharides, and polyols (FODMAPs)-eliminating diets. These are

Table I Serotonergic and prosecretory agents

\begin{tabular}{|c|c|c|c|c|}
\hline 5- $\mathrm{HT}_{3}$ antagonists & Agent & & Adverse events & Indication \\
\hline \multirow[t]{2}{*}{$\begin{array}{l}\downarrow \text { Bowel sensitivity } \\
\downarrow \text { Intestinal motility }\end{array}$} & Alosetron & $\begin{array}{l}\text { Recommendation: weak } \\
\text { Evidence: moderate }\end{array}$ & $\begin{array}{l}\text { Severe constipation } \\
\text { Ischemic colitis }\end{array}$ & $\begin{array}{l}\text { Only for woman suffering with } \\
\text { severe IBS-D that is disabling }\end{array}$ \\
\hline & $\begin{array}{l}\text { Cilansetron } \\
\text { Ramosetron* }\end{array}$ & Not available & Constipation & $\begin{array}{l}\text { Poorly introduced into clinical } \\
\text { practice }\end{array}$ \\
\hline \multicolumn{5}{|l|}{ 5- $\mathrm{HT}_{4}$ agonists } \\
\hline \multirow[t]{2}{*}{$\begin{array}{l}\uparrow \text { Secretion } \\
\uparrow \text { Peristaltic reflex } \\
\uparrow \text { Intestinal motility }\end{array}$} & Tegaserod & $\begin{array}{l}\text { Better than placebo } \\
\text { in promoting intestinal } \\
\text { motility }\end{array}$ & $\begin{array}{l}\text { Cardiovascular effects } \\
\text { Nausea, diarrhea, headache }\end{array}$ & $\begin{array}{l}\text { Women with IBS-C (withdrawn } \\
\text { in USA) }\end{array}$ \\
\hline & Prucalopride & Not approved in IBS-D & Nausea, diarrhea, headache & $\begin{array}{l}\text { Chronic Constipation (Canada } \\
\text { and European Union) }\end{array}$ \\
\hline \multicolumn{5}{|l|}{ Mixed $5-\mathrm{HT}_{3} / 5-\mathrm{HT}_{4}$} \\
\hline & Renzapride & Equal to placebo & $\begin{array}{l}\text { Nausea, diarrhea, headache, } \\
\text { arrhythmias }\end{array}$ & $\begin{array}{l}\text { Not available in most } \\
\text { developed countries }\end{array}$ \\
\hline & Cisapride & Withdrawn & & \\
\hline \multicolumn{5}{|l|}{ Prosecretory agents } \\
\hline \multirow[t]{2}{*}{$\begin{array}{l}\uparrow \text { Secretion } \\
\downarrow \text { Bowel sensitivity }\end{array}$} & $\begin{array}{l}\text { Lubiprostone } \\
\text { (CIC-2 agonist) }\end{array}$ & $\begin{array}{l}\text { Recommendation: strong } \\
\text { Evidence: high }\end{array}$ & Diarrhea & IBS-C \\
\hline & $\begin{array}{l}\text { Linaclotide } \\
\text { (GCC agonist) }\end{array}$ & $\begin{array}{l}\text { Recommendation: strong } \\
\text { Evidence: moderate }\end{array}$ & Diarrhea, flatulence & IBS-C \\
\hline
\end{tabular}

Note: *Available in Japan, Korea, and Thailand.

Abbreviations: $\uparrow$, increase; $\downarrow$, decrease; CIC-2, chloride channel type 2; GCC, guanylate cyclase-C; HT, hydroxytryptamine receptor; IBS-C, constipation-predominant irritable bowel syndrome; IBS-D, diarrhea-predominant irritable bowel syndrome. 
Table 2 Strength of the recommendations and quality of evidences of therapeutic options for IBS associated with constipation

\begin{tabular}{llll}
\hline Strategies & Mechanism & Recommendation & Quality of evidence \\
\hline Fibers & $\begin{array}{l}\text { Benefit on constipation but } \\
\text { may worsen bloating and } \\
\text { abdominal discomfort }\end{array}$ & Weak & Moderate \\
$\begin{array}{l}\text { Fluid } \\
\text { Probiotics }\end{array}$ & $\begin{array}{l}\text { Influence of a real benefit is lacking } \\
\text { and food fermentation through } \\
\text { positive effect on intestinal } \\
\text { microbiota composition }\end{array}$ & Weak & Very low \\
The effect is mainly on constipation \\
with minor or no benefit on IBS \\
symptoms \\
Minority of patients have benefit \\
on bloating and meteorism \\
Prokinetic and secretive effect; might \\
reduce visceral hypersensitivity \\
Prokinetic and secretive effect; might \\
Linaclotide
\end{tabular}

Abbreviation: IBS, irritable bowel syndrome.

carbohydrates found in foods such as apples, pears, honey, sweeteners, onions, and milk (Table 3), but not all "sugars" are part of this group. ${ }^{89}$ They are characterized by being osmotic, mainly not digested or absorbed, and thus fermented by the intestinal bacteria.

Review papers have encouraged application of a FODMAP eliminating diet as a first-line dietary approach to manage functional symptoms seen in IBS. ${ }^{90}$ However, further evaluation is necessary since the low FODMAPs diet has been also shown to change the intestinal microbiota, and further assessments of its nutritional implications are required..$^{91}$

\section{Fiber}

Most physicians recommend the use of dietary fiber and bulking agents to regularize bowel function and to reduce meteorism and pain in patients with IBS. The level of evidences supporting this recommendation, however, is poor.

The recommended adult daily intake of fiber ranges between 20 and $35 \mathrm{~g} / \mathrm{d}$. Often, many IBS-C patients modify their dietary fiber intake prior to the assessment of the physician with the belief that fiber supplementation has a beneficial effect on their symptoms. ${ }^{92}$ Nevertheless, fiber supplementation is also the treatment most often prescribed in the primary care system. ${ }^{93}$

The term "dietary fiber" includes carbohydrates which are not hydrolyzed or absorbed in the upper digestive tract and therefore reach the colon where they are fermented by the gut microbiota, producing short-chain fatty acids and gases. Depending on their solubility in water, fibers are subdivide into soluble and insoluble. An increase of the daily intake of fiber is able to determine softer and bulkier stools, promoting peristalsis and facilitating defecation.

In a randomized placebo-controlled trial, ${ }^{94}$ Bijkerk et al compared the efficacy of soluble (psyllium) and insoluble (bran) fiber versus placebo in IBS patients. They reported an improvement in the severity of symptoms in the psyllium arm compared to placebo except for abdominal pain or health-related quality of life. Bran did not lead to significant changes in terms of symptoms and is found to be poorly tolerated by patients.

Partially hydrolyzed guar gum is a soluble, non-gelling fiber that has been shown to reduce symptoms and decrease abdominal pain in patients with IBS-C. ${ }^{95}$ Moreover, partially hydrolyzed guar gum seems to also have prebiotic properties (eg, it increases the colonic contents of short-chain fatty acids, lactobacilli, and Bifidobacterium) ${ }^{96,97}$ For this reason, it has been used in combination with rifaximin for the management of small intestinal bacterial overgrowth. ${ }^{98}$

In a recent meta-analysis, Moayyedi et al showed that soluble, but not insoluble, fiber was effective in reducing overall symptoms. ${ }^{99}$ Their study showed that there is a moderate quality of evidence that fibers are effective in IBS patients. Taking into consideration their low costs and minimal side effects, fibers still represent so far a first fundamental approach in the therapy of patients with IBS.

\section{Osmotic laxatives}

Similar to fibers, laxatives remain an appropriate therapy for many patients with IBS-C because of their relative safety, low cost, and availability. ${ }^{100}$ 


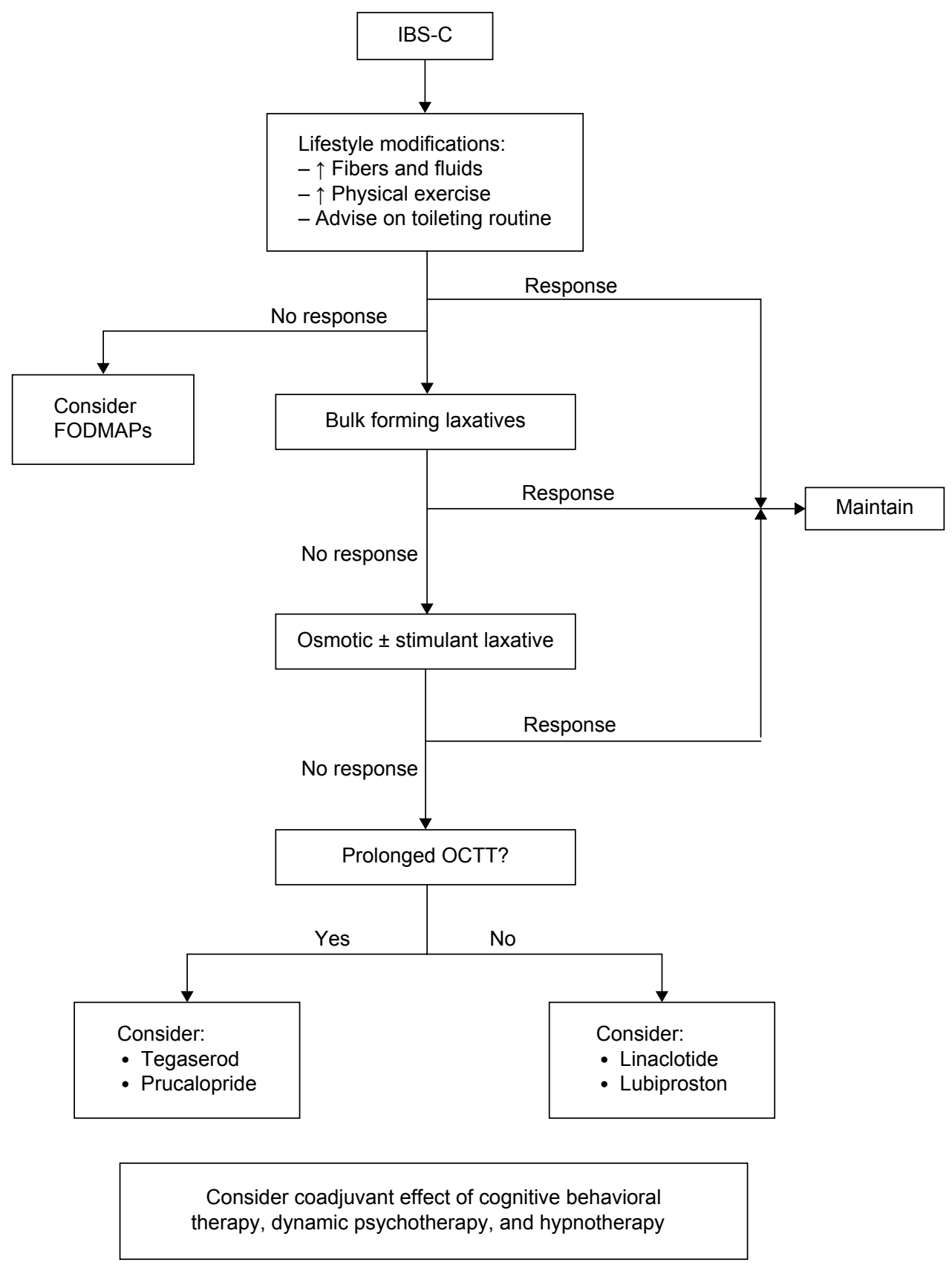

Figure 2 Therapeutic flowchart of patients referring for IBS-C

Notes: Use of prucalopride in IBS is considered off-label. Although illustrated at the end of therapeutic process, psychological approaches might be considered alongside the other treatment options.

Abbreviations: $\uparrow$, increase; FODMAPs, fermentable, oligo-, di-, monosaccharides, and polyols; IBS, irritable bowel syndrome; IBS-C, IBS constipation variant; OCTT, orocecal transit time.

Laxatives can be classified according to the principal mechanism of action as:

- osmotic laxatives; they are represented by ions or molecules that are osmotically active and poorly absorbed in the gut, and that induce secretion of water inside the intestinal lumen.

- secretagogues and agents acting directly on epithelial cells, nerve cells, and smooth muscle of the gut; several compounds play a laxative effect through different mechanisms of motor activity and bowel control, and also act on the mucosal transport and motility.

- lubricating agents; mineral oils (such as Vaseline oil) can be administered both orally and rectally; they help fecal expulsion and create a soft fecal mass.

- Stimulant laxatives, for example, sodium picosulfate and bisacodyl, are usually used in clinical practice, but their effectiveness in IBS-C has not been well demonstrated yet. 
Table 3 Principal foods containing fermentable, oligo-, di-, monosaccharides, and polyols

\begin{tabular}{ll}
\hline "Sugars" & Foods \\
\hline Oligosaccharides: & \\
- Fructans & - Wheat, rye, onions, garlic, \\
& asparagus, broccoli, cabbage, \\
& pasta, chicory, etc. \\
- Galactans & - Legumes \\
Disaccharide lactose & Milk, cheeses, and yogurt \\
Monosaccharide fructose & Honey, apple, pear, mango, \\
& high fructose corn syrup, fruit \\
& juice, etc. \\
Polyols & Apples, pears, apricot, stone \\
& fruit, sweeteners, confectionary, \\
& mushrooms, etc. \\
\hline
\end{tabular}

Osmotic laxatives, such as polyethylene glycol (PEG), milk of magnesia, and sorbitol are often recommended for IBS-C. However, data proving their efficacy on constipation come principally from studies on chronic constipation. The 2005 American College of Gastroenterology summary statement gave PEG a grade A recommendation for the treatment of patients with chronic constipation. ${ }^{101}$ Moreover, Dipalma et al published a randomized, multicenter, placebo-controlled trial of PEG laxative for chronic treatment of chronic constipation. ${ }^{102}$ In this trial, 304 subjects (75 of which were 65 years old) who met the definition of constipation based on modified rome criteria were enrolled. One hundred and seventy subjects followed therapy for 6 months. The study proved PEG's safety and efficacy.

Finally, a recent placebo-controlled trial in IBS-C highlighted the power of PEG in increasing bowel frequency but also its limited effect on abdominal pain. ${ }^{103}$

\section{Serotonergic agents}

These agents fall into three categories according to their mechanism of action: $5-\mathrm{HT}_{3}$ antagonists, $5-\mathrm{HT}_{4}$ agonists, and mixed 5- $\mathrm{HT}_{3}$ antagonists $/ 5-\mathrm{HT}_{4}$ agonists.

$5-\mathrm{HT}_{3}$ antagonists have shown a potential role in reducing visceral sensitivity (ie, pain threshold) but to the detriment of intestinal motility. For this reason, they are not suitable for IBS-C variant.

5- $\mathrm{HT}_{4}$ agonists increase intestinal secretion, peristaltic reflex, and gastrointestinal transit. Among these, tegaserod showed good efficacy compared to placebo. The initial dose suggested is $6 \mathrm{mg}$ orally twice a day before meals for 4-6 weeks. In case of benefit, it should be maintained for other 4-6 weeks. However, due to cardiac adverse events, it has been removed from the USA market and its indication limited to females with the IBS-C variant. As mentioned before, prucalopride also provided good efficacy in constipation but not in discomfort relief. Thus, it is available in Canada and the European Union for patients with chronic constipation (initial dose: $2 \mathrm{mg}$ /day orally for 4 weeks without food; maintenance: 12 weeks; then reevaluation). Solid data in IBS patients are still awaited.

Mixed 5- $\mathrm{HT}_{3}$ antagonists $/ 5-\mathrm{HT}_{4}$ agonists were supposed to mitigate the side effects of serotonergic agents while preserving their action on visceral sensitivity and secretion. However, several studies did not show a significant benefit compared to placebo. ${ }^{9}$ Cisapride, one of the most studied and employed drugs in clinical practice, is no longer available in most developed countries.

\section{Prosecretory agents Lubiprostone}

The primary mechanism of action of lubiprostone is the capability to activate specific type- 2 chloride channels (ClC-2) on the apical membrane of the enterocyte. ${ }^{104}$ They are involved in ion and fluid transport across epithelial membrane. Once channels are opened, chloride enters the enterocyte in the basal membrane through the action of $\mathrm{Na}-\mathrm{K}-2 \mathrm{Cl}$ active cotransporters, creating the electrochemical gradient favoring chloride secretion leading to an overall concentration-dependent increase in intestinal fluid secretion without altering serum sodium and potassium levels. ${ }^{105}$ These mechanisms explain how lubiprostone increases the number of CSBMs per week, but its action on other IBS-C symptoms, such as the abdominal pain score, is only partially characterized and needs further investigations. The suggested dosage is $8 \mu \mathrm{g}$ orally twice a day with food and water. The most common treatment-related adverse events ( $>1 \%$ of patients) involved the gastrointestinal system: diarrhea $(6.5 \%)$, nausea $(6.3 \%)$, abdominal distention (3.7\%), abdominal pain (2.9\%), flatulence (2.1\%), upper abdominal pain (1.9\%), and vomiting (1.2\%). The genesis of lubiprostone's adverse events remains speculative. Moreover, the very different baseline characteristics between patients with IBS-C in terms of abdominal symptoms, visceral sensitivity, and somatization might alter patients' reporting of adverse events. ${ }^{106}$

\section{Linaclotide}

Linaclotide, a 14-amino acid synthetic peptide, is a first-inclass, high-affinity guanylate cyclase $\mathrm{C}$ (GC-C) agonist. It is homologous to the paracrine peptide hormones guanylin and uroguanylin, which are the endogenous activators of GC-C. ${ }^{107}$ This drug may modulate the intestinal physiology in two 
ways. Firstly, GC-C activation leads to increased intracellular concentrations of the second messenger cyclic guanosine monophosphate (cGMP). ${ }^{107}$ Elevated intracellular cGMP levels activate the cGMP-dependent protein kinase II, leading to the phosphorylation and activation of the cystic fibrosis transmembrane conductance regulator (CFTR). ${ }^{108,109}$ CFTR activation results in the secretion of chloride and bicarbonate ions and inhibition of sodium absorption, leading to increased water flow into the intestine and the acceleration of gastrointestinal transit. ${ }^{107-110}$ Secondly, linaclotide has also been shown to reduce visceral hypersensitivity in stress- and inflammationinduced animal models of visceral pain. ${ }^{111}$ A recent preclinical study suggests that, upon GC-C activation, cGMP is actively transported across the basolateral membrane of the intestinal epithelium into the submucosal space where it acts to reduce the mechanosensitivity of colonic nociceptors, in both healthy mice and a mouse model of visceral hypersensitivity. ${ }^{112}$ The recommended dosage is $290 \mu \mathrm{g}$ orally once a day before meals. The most frequent adverse events with linaclotide were diarrhea, abdominal pain, flatulence, headache, viral gastroenteritis, and abdominal distension. ${ }^{113}$ Diarrhea, which is the most common, is estimated to occur in less the $20 \%$ of patients and it is probably due to increased fluid secretion and accelerated colonic transit. ${ }^{114-116}$

\section{Psychological therapies}

The recent monograph on IBS and chronic idiopathic constipation by the American College of Gastroenterology has recognized a potential role of psychological therapies in IBS. Specifically, hypnotherapy, cognitive behavioral therapy, and dynamic psychotherapy provided significant benefits compared to placebo. ${ }^{117}$ Other approaches showed no significant effects; however, the complexity of conducting blind and controlled studies that allow an objective comparison of these interventions must be acknowledged.

\section{Conclusion}

IBS is a multifactorial functional disorder that involves mainly the lower gastrointestinal tract. The major problem met by doctors is the relative paucity of therapeutic options available and their often limited efficacy. This is particularly emphasized in the IBS-C variant. Incomplete understanding of the pathophysiology, overlap with other functional disorders, inter-/intraindividual variability, and patient's distress contribute to the failure. We believe that a standardized and step-wise approach to these patients might partially improve the success rate of the treatment and guarantee uniformity and therapeutical continuity in a setting where multiple investigators are often involved. In the context of functional disorders, a dedicated doctor-patient relationship still remains of utmost importance.

\section{Author contributions}

All authors contributed toward data analysis, drafting and revising the paper and agree to be accountable for all aspects of the work.

\section{Disclosure}

The authors report no conflicts of interest in this work.

\section{References}

1. Chang L. Review article: epidemiology and quality of life in functional gastrointestinal disorders. Aliment Pharmacol Ther. 2004;20 Suppl 7: 31-39.

2. Rome Foundation. Guidelines - Rome III Diagnostic Criteria for Functional Gastrointestinal Disorders. J Gastrointestin Liver Dis. 2006;15:307-312.

3. American College of Gastroenterology Task Force on Irritable Bowel Syndrome, Brandt LJ, Chey WD, et al. An evidence-based position statement on the management of irritable bowel syndrome. Am J Gastroenterol. 2009;104 Suppl 1:S1-S35.

4. Hungin AP, Whorwell PJ, Tack J, Mearin F. The prevalence, patterns and impact of irritable bowel syndrome: an international survey of 40,000 subjects. Aliment Pharmacol Ther. 2003;17:643-650.

5. Chang JY, Talley NJ. An update on irritable bowel syndrome: from diagnosis to emerging therapies. Curr Opin Gastroenterol. 2011;27: 72-78.

6. Mayer EA, Naliboff BD, Chang L. Basic pathophysiologic mechanisms in irritable bowel syndrome. Dig Dis. 2001;19:212-218.

7. Hauser G, Pletikosic S, Tkalcic M. Cognitive behavioral approach to understanding irritable bowel syndrome. World J Gastroenterol. 2014; 20:6744-6758.

8. Ohman L, Simrén M. Pathogenesis of IBS: role of inflammation, immunity and neuroimmune interactions. Nat Rev Gastroenterol Hepatol. 2010;7:163-173.

9. Ragnarsson G, Bodemar G. Division of the irritable bowel syndrome into subgroups on the basis of daily recorded symptoms in two outpatient samples. Scand J Gastroenterol. 1999;34:993-1000.

10. Mearin F, Balboa A, Badía X, et al. Irritable bowel syndrome subtypes according to bowel habit: revisiting the alternating subtype. Eur J Gastroenterol Hepatol. 2003;15:165-172.

11. Mearin F, Baró E, Roset M, Badía X, Zárate N, Pérez I. Clinical patterns over time in irritable bowel syndrome: symptom instability and severity variability. Am J Gastroenterol. 2004;99:113-121.

12. Hulisz D. The burden of illness of irritable bowel syndrome: current challenges and hope for the future. J Manag Care Pharm. 2004; 10:299-309.

13. Frank L, Kleinman L, Rentz A, Ciesla G, Kim JJ, Zacker C. Health-related quality of life associated with irritable bowel syndrome: comparison with other chronic diseases. Clin Ther. 2002;24: 675-689.

14. Longstreth GF, Wilson A, Knight K, et al. Irritable bowel syndrome, health care use, and costs: a U.S. managed care perspective. Am J Gastroenterol. 2003;98:600-607.

15. Davis RH. Overcoming barriers in irritable bowel syndrome with constipation (IBS-C). J Fam Pract. 2009;58:S3-S7. 
16. Drossman DA, Morris CB, Schneck S, et al. International survey of patients with IBS: symptom features and their severity, health status, treatments, and risk taking to achieve clinical benefit. J Clin Gastroenterol. 2009;43:541-550.

17. Müller-Lissner S, Tack J, Feng Y, Schenck F, Specht Gryp R. Levels of satisfaction with current chronic constipation treatment options in Europe - an internet survey. Aliment Pharmacol Ther. 2013;37(1):137-145.

18. Akehurst R, Kaltenthaler E. Treatment of irritable bowel syndrome: a review of randomised controlled trials. Gut. 2001;48:272-282.

19. Dorn SD, Kaptchuk TJ, Park JB, et al. A meta-analysis of the placebo response in complementary and alternative medicine trials of irritable bowel syndrome. Neurogastroenterol Motil. 2007;19: 630-637.

20. Elsenbruch S. How positive and negative expectations shape the experience of visceral pain. Handb Exp Pharmacol. 2014;225:97-119.

21. Layer P, Stanghellini V. Review article: Linaclotide for the management of irritable bowel syndrome with constipation. Aliment Pharmacol Ther. 2014;39:371-384.

22. Soares RL. Irritable bowel syndrome: a clinical review. World $J$ Gastroenterol. 2014;20:12144-12160.

23. Karantanos T, Markoutsaki T, Gazouli M, Anagnou NP, Karamanolis DG. Current insights in to the pathophysiology of Irritable Bowel Syndrome. Gut Pathog. 2010;2:3.

24. Ohman L, Simrén M. New insights into the pathogenesis and pathophysiology of irritable bowel syndrome. Dig Liver Dis. 2007;39: 201-215.

25. Saito YA. The role of genetics in IBS. Gastroenterol Clin North Am. 2011;40(1):45-67.

26. Locke GR 3rd, Zinsmeister AR, Talley NJ, Fett SL, Melton LJ. Familial association in adults with functional gastrointestinal disorders. Mayo Clin Proc. 2000;75(9):907-912.

27. Adam B, Liebregts T, Holtmann G. Mechanisms of disease: genetics of functional gastrointestinal disorders-searching the genes that matter Nat Clin Pract Gastroenterol Hepatol. 2007;4(2):102-110.

28. Camilleri M, Katzka DA. Irritable bowel syndrome: methods, mechanisms, and pathophysiology. Genetic epidemiology and pharmacogenetics in irritable bowel syndrome. Am Physiol Gastrointest Liver Physiol. 2012;302:G1075-1084.

29. Drossman DA, Camilleri M, Mayer EA, Whitehead WE. AGA technical review on irritable bowel syndrome. Gastroenterology. 2002;123:2108-2131.

30. Serra J, Azpiroz F, Malagelada JR. Impaired transit and tolerance of intestinal gas in the irritable bowel syndrome. Gut. 2001;48;14-19.

31. Prott G, Shim L, Hansen R, Kellow J, Malcolm A. Relationships between pelvic floor symptoms and function in irritable bowel syndrome. Neurogastroenterol Motil. 2010;22:764-769.

32. Barbara G, De Giorgio R, Stanghellini V, Cremon C, Salvioli B, Corinaldesi R. New pathophysiological mechanisms in irritable bowel syndrome. Aliment Pharmacol Ther. 2004;20 Suppl 2:1-9.

33. Posserud I, Syrous A, Lindström L, Tack J, Abrahamsson H, Simren M. Altered rectal perception in irritable bowel syndrome is associated with symptom severity. Gastroenterology. 2007;133:1113-1123.

34. Bouin M, Plourde V, Boivin M, et al. Rectal distention testing in patients with irritable bowel syndrome: sensitivity, specificity, and predictive values of pain sensory thresholds. Gastroenterology. 2002; 122:1771-1777.

35. Costantini M, Sturniolo GC, Zaninotto G, et al. Altered esophageal pain threshold in irritable bowel syndrome. Dig Dis Sci. 1993;38: 206-212.

36. Trimble KC, Farouk R, Pryde A, Douglas S, Heading RC. Heightened visceral sensation in functional gastrointestinal disease is not sitespecific. Evidence for a generalized disorder of gut sensitivity. Dig Dis Sci. 1995;40:1607-1613.

37. Accarino AM, Azpiroz F, Malagelada JR. Selective dysfunction of mechanosensitive intestinal afferents in irritable bowel syndrome. Gastroenterology. 1995;108:636-643.
38. Simrén M, Abrahamsson H, Björnsson ES. An exaggerated sensory component of the gastrocolonic response in patients with irritable bowel syndrome. Gut. 2001;48:20-27.

39. Posserud I, Agerforz P, Ekman R, Björnsson ES, Abrahamsson H, Simrén M. Altered visceral perceptual and neuroendocrine response in patients with irritable bowel syndrome during mental stress. Gut. 2004;53:1102-1108

40. Naliboff BD, Berman S, Suyenobu B, et al. Longitudinal change in perceptual and brain activation response to visceral stimuli in irritable bowel syndrome patients. Gastroenterology. 2006;131:352-365.

41. Van Oudenhove L, Demyttenaere K, Tack J, Aziz Q. Central nervous system involvement in functional gastrointestinal disorders. Best Pract Res Clin Gastroenterol. 2004;18:663-680.

42. Elsenbruch S. Abdominal pain in Irritable Bowel Syndrome: a review of putative psychological, neural and neuro-immune mechanisms. Brain Behav Immun. 2011;25:386-394.

43. Al Omran Y, Aziz Q. The brain-gut axis in health and disease. Adv Exp Med Biol. 2014;817:135-153.

44. Mertz HR. Overview of functional gastrointestinal disorders: dysfunction of the brain-gut axis. Gastroenterol Clin North Am. 2003;32:463-476.

45. Chitkara DK, Van Tilburg MA, Blois-Martin N, Whitehead WE. Early life risk factors that contribute to irritable bowel syndrome in adults: a systematic review. Am J Gastroenterol. 2008;103:765-774.

46. Hyland NP, Quigley EM, Brint E. Microbiota-host interactions in irritable bowel syndrome: epithelial barrier, immune regulation and brain-gut interactions. World J Gastroenterol. 2014;20: 8859-8866.

47. Longstreth GF, Thompson WG, Chey WD, Houghton LA, Mearin F, Spiller RC. Functional bowel disorders. Gastroenterology. 2006;130: 1480-1491.

48. Ford AC, Talley NJ, Veldhuyzen Van Zanten SJ, Vakil NB, Simel DL, Moayyedi P. Will the history and physical examination help establish that irritable bowel syndrome is causing this patient's lower gastrointestinal tract symptoms? JAMA. 2008;300:1793-1805.

49. Engsbro AL, Begtrup LM, Kjeldsen J, et al. Patients suspected of irritable bowel syndrome - crosssectional study exploring the sensitivity of Rome III criteria in primary care. Am J Gastroenterol. 2013; 108:972-980.

50. Deepak P, Ehrenpreis ED. Constipation. Dis Mon. 2011;57:511-517.

51. Quigley EM, Abdel-Hamid H, Barbara G, et al. A global perspective on irritable bowel syndrome: a consensus statement of the World Gastroenterology Organisation Summit Task Force on irritable bowel syndrome. J Clin Gastroenterol. 2012;46:356-366.

52. Spiller R, Aziz Q, Creed F, et al. Guidelines on the irritable bowel syndrome: mechanisms and practical management. Gut. 2007; 56:1770-1798.

53. Hammer J, Eslick GD, Howell SC, Altiparmak E, Talley NJ. Diagnostic yield of alarm features in irritable bowel syndrome and functional dyspepsia. Gut. 2004;53:666-672.

54. Ford AC, Veldhuyzen Van Zanten SJ, Rodgers CC, Talley NJ, Vakil NB, Moayyedi P. Diagnostic utility of alarm features for colorectal cancer: systematic review and meta-analysis. Gut. 2008;57: 1545-1553.

55. Gunnarsson J, Simrén M. Efficient diagnosis of suspected functional bowel disorders. Nat Clin Pract Gastroenterol Hepatol. 2008; 5:498-507.

56. Wald A. Pathophysiology, diagnosis and current management of chronic constipation. Nat Clin Pract Gastroenterol Hepatol. 2006;3:90-100.

57. de Bortoli N, Martinucci I, Bellini M, et al. Overlap of functional heartburn and gastroesophageal reflux disease with irritable bowel syndrome. World J Gastroenterol. 2013;19:5787-5797.

58. Talley NJ, Dennis EH, Schettler-Duncan VA, Lacy BE, Olden KW, Crowell MD. Overlapping upper and lower gastrointestinal symptoms in irritable bowel syndrome patients with constipation or diarrhea. Am J Gastroenterol. 2003;98:2454-2459. 
59. Wong RK, Palsson OS, Turner MJ, et al. Inability of the Rome III criteria to distinguish functional constipation from constipation-subtype irritable bowel syndrome. Am J Gastroenterol. 2010;105:2228-2234.

60. Shekhar C, Monaghan PJ, Morris J, et al. Rome III functional constipation and irritable bowel syndrome with constipation are similar disorders within a spectrum of sensitization, regulated by serotonin. Gastroenterology. 2013;145:749-757.

61. Rey E, Balboa A, Mearin F. Chronic constipation, irritable bowel syndrome with constipation and constipation with pain/discomfort: similarities and differences. Am J Gastroenterol. 2014;109:876-884.

62. Furnari M, Savarino E, Bruzzone L, et al. Reassessment of the role of methane production between irritable bowel syndrome and functional constipation. J Gastrointestin Liver Dis. 2012;21:157-163.

63. Gemignani L, Savarino V, Ghio M, et al. Lactulose breath test to assess oro-cecal transit delay and estimate esophageal dysmotility in scleroderma patients. Semin Arthritis Rheum. 2013;42(5):522-529.

64. Cremonini F, Lembo A. IBS with constipation, functional constipation, painful and non-painful constipation: e Pluribus...Plures? Am J Gastroenterol. 2014;109:885-886.

65. Chey WD, Kurlander J, Eswaran S. Irritable bowel syndrome: a clinical review. JAMA. 2015;313(9):949-958.

66. O’Connor OJ, McSweeney SE, McWilliams S, et al. Role of radiologic imaging in irritable bowel syndrome: evidence-based review. Radiology. 2012;262:485-494.

67. McNally MA, Locke GR, Zinsmeister AR, Schleck CD, Peterson J, Talley NJ. Biliary events and an increased risk of new onset irritable bowel syndrome: a population-based cohort study. Aliment Pharmacol Ther. 2008;28(3):334-343.

68. American College of Gastroenterology Task Force on Irritable Bowel Syndrome, Brandt LJ, Chey WD, et al. An evidence-based position statement on the management of irritable bowel syndrome. Am J Gastroenterol. 2009;104 Suppl 1:S1-S35.

69. Klauser AG, Voderholzer WA, Schindlbeck NE, Müller-Lissner SA. Functional diagnostic work-up in patients with irritable bowel syndrome. Z Gastroenterol. 1996;34:273-278.

70. Koide A, Yamaguchi T, Odaka T, et al. Quantitative analysis of bowel gas using plain abdominal radiograph in patients with irritable bowel syndrome. Am J Gastroenterol. 2000;95:1735-1741.

71. Törnblom H, Van Oudenhove L, Sadik R, Abrahamsson H, Tack J, Simrén M. Colonic transit time and IBS symptoms: what's the link? Am J Gastroenterol. 2012;107:754-760.

72. Horikawa Y, Mieno H, Inoue M, Kajiyama G. Gastrointestinal motility in patients with irritable bowel syndrome studied by using radiopaque markers. Scand J Gastroenterol. 1999;34:1190-1195.

73. Cosentino M, Beati C, Fornari S, et al. Defaecography and colonic transit time for the evaluation of female patients with obstructed defaecation. Radiol Med. 2014;119:813-819.

74. Savarino E, Savarino V, Fox M,et al. Measurement of oro-caecal transit time by magnetic resonance imaging. Eur Radiol. 2015. [Epub ahead of print] PMID: 25576231.

75. Brandão AC, Ianez P. MR imaging of the pelvic floor: defecography. Magn Reson Imaging Clin N Am. 2013;21:427-445.

76. Camilleri M. Review article: new receptor targets for medical therapy in irritable bowel syndrome. Aliment Pharmacol Ther. 2010;31:35-46.

77. Corsetti M, Tack J. FDA and EMA end points: which outcome end points should we use in clinical trials in patients with irritable bowel syndrome? Neurogastroenterol Motil. 2013;25:453-457.

78. U.S. Department of Health and Human Services Food and Drug Administration Center for Drug Evaluation and Research (CDER). Guidance for Industry Irritable Bowel Syndrome - Clinical Evaluation of Drugs for Treatment. 2012. Available from: http://www.fda.gov/downloads/ Drugs/Guidances/UCM205269.pdf. Accessed March 23, 2015.

79. European Medicines Agency. Guideline on the evaluation of medicinal products for the treatment of irritable bowel syndrome. EMA/CHMP/60337/2013. (CPMP/EWP/785/97 Rev. 1). Available from: http://www.ema.europa.eu/docs/en_GB/document_library/Scientific_guideline/2014/09/WC500173457.pdf. Accessed March 23, 2015.
80. Tack J, Corsetti M. Prucalopride: evaluation of the pharmacokinetics, pharmacodynamics, efficacy and safety in the treatment of chronic constipation. Expert Opin Drug Metab Toxicol. 2012;8:1327-1335.

81. Tack J, Camilleri M, Chang L, et al. Systematic review: cardiovascular safety profile of 5-HT(4) agonists developed for gastrointestinal disorders. Aliment Pharmacol Ther. 2012;35:745-767.

82. Amitiza: FDA Product Information. 2013. Available from: http:// www.fda.gov/NewsEvents/Newsroom/PressAnnouncements/2008/ ucm 1 16889.htm

83. Linaclotide: FDA Product Information. 2013. Available from: http://www.fda.gov/NewsEvents/Newsroom/PressAnnouncements/ ucm 317505.htm

84. Linaclotide: EMA Summary of Product Characteristics. 2013. Available from: http://www.ema.europa.eu/docs/en_GB/document_library/ EPAR_-_Product_Information/human/002490/WC500135622.pdf

85. Jones J, Boorman J, P Cann P, et al. British Society of Gastroenterology guidelines for the management of the irritable bowel syndrome. Gut. 2000;47 Suppl 2:ii1-ii19.

86. Aller R, de Luis DA, Izaola O, et al. Effects of a high-fiber diet on symptoms of irritable bowel syndrome: a randomized clinical trial. Nutrition. 2004;20:735-737.

87. Eswaran S, Muir J, Chey WD. Fiber and functional gastrointestinal disorders. Am J Gastroenterol. 2013;108:718-727.

88. Shepherd SJ, Parker FC, Muir JG, Gibson PR. Dietary triggers of abdominal symptoms in patients with irritable bowel syndrome: randomized placebo-controlled evidence. Clin Gastroenterol Hepatol. 2008;6:765-771

89. Shepherd SJ, Lomer MC, Gibson PR. Short-chain carbohydrates and functional gastrointestinal disorders. Am J Gastroenterol. 2013;108:707-717.

90. Halmos EP, Power VA, Shepherd SJ, Gibson PR, Muir JG. A diet low in FODMAPs reduces symptoms of irritable bowel syndrome. Gastroenterol. 2014;146:67-75.

91. Halmos EP, Christopherson CT, Bird AR, Shepherd SJ, Gibson PR, Muir JG. Diets that differ in their FODMAP content alter the colonic luminal microenvironment. Gut. 2015;64(1):93-100.

92. Alaimo K, McDowell MA, Briefel RR, et al. Dietary intake of vitamins, minerals, and fiber of persons ages 2 months and over in the United States: Third National Health and Nutrition Examination Survey, Phase 1, 1988-1991. Adv Data. 1994;(258):1-28.

93. Bellini M, Gambaccini D, Salvadori S, et al. Management of chronic constipation in general practice. Tech Coloproctol. 2014;18: 543-549.

94. Bijkerk CJ, de Wit NJ, Muris JW, Whorwell PJ, Knottnerus JA, Hoes AW. Soluble or insoluble fibre in irritable bowel syndrome in primary care? Randomised placebo controlled trial. BMJ. 2009;339: b3154.

95. Giannini EG, Mansi C, Dulbecco P, Savarino V. Role of partially hydrolyzed guar gum in the treatment of irritable bowel syndrome. Nutrition. 2006;22:334-342.

96. Tuohy KM, Kolida S, Lustenberger AM, Gibson GR. The prebiotic effects of biscuits containing partially hydrolysed guar gum and fructo-oligosaccharides - a human volunteer study. $\mathrm{Br} J$ Nutr. 2001;86:341-348.

97. Takahashi H, Wako N, Okubo T, Ishihara N, Yamanaka J, Yamamoto T. Influence of partially hydrolysed guar gum on constipation in women. J Nutr Sci Vitaminol (Tokyo). 1994;40:251-259.

98. Furnari M, Parodi A, Gemignani L, et al. Clinical trial: the combination of rifaximin with partially hydrolysed guar gum is more effective than rifaximin alone in eradicating small intestinal bacterial overgrowth. Aliment Pharmacol Ther. 2010;32:1000-1006.

99. Moayyedi P, Quigley EM, Lacy BE, et al. The effect of fiber supplementation on irritable bowel syndrome: a systematic review and meta-analysis. Am J Gastroenterol. 2014;109:1367-1374.

100. Jadallah KA, Kullab SM, Sanders DS. Constipation-predominant irritable bowel syndrome: a review of current and emerging drug therapies. World J Gastroenterol. 2014;20:8898-8909. 
101. American College of Gastroenterology Chronic Constipation Task Force. An evidence-based approach to the management of chronic constipation in North America. Am J Gastroenterol. 2005;100 Suppl 1: S1-S4.

102. Dipalma JA, Cleveland MV, McGowan J, Herrera JL. A randomized, multicenter, placebo-controlled trial of polyethylene glycol laxative for chronic treatment of chronic constipation. Am J Gastroenterol. 2007;102:1436-1441.

103. Chapman RW, Stanghellini V, Geraint M, Halphen M. Randomized clinical trial: macrogol/PEG 3350 plus electrolytes for treatment of patients with constipation associated with irritable bowel syndrome. Am J Gastroenterol. 2013;108:1508-1515.

104. Cuppoletti J, Malinowska DH, Tewari KP, et al. SPI-0211 activates T84 cell chloride transport and recombinant human $\mathrm{ClC}-2$ chloride currents. Am J Physiol Cell Physiol. 2004;287:C1173-C1183.

105. Barrett KE, Keely SJ. Chloride secretion by the intestinal epithelium: molecular basis and regulatory aspects. Annu Rev Physiol. 2000; 62:535-572.

106. Lackner J, Jaccard J, Baum C, et al. Patient-reported outcomes for irritable bowel syndrome are associated with patients' severity ratings of gastrointestinal symptoms and psychological factors. Clin Gastroenterol Hepatol. 2011;9:957-964.

107. Bharucha AE, Waldman SA. Taking a lesson from microbial diarrheagenesis in the management of chronic constipation. Gastroenterology. 2010;138:813-817.

108. Giannella RA, Mann EA. E. coli heatstable enterotoxin and guanylyl cyclase C: new functions and unsuspected actions. Trans Am Clin Climatol Assoc. 2003;114:67-85.

109. Schlossmann J, Feil R, Hofmann F. Insights into cGMP signalling derived from cGMP kinase knockout mice. Front Biosci. 2005; 10:1279-1289.

110. Busby RW, Bryant AP, Bartolini WP, et al. Linaclotide, through activation of guanylate cyclase $\mathrm{C}$, acts locally in the gastrointestinal tract to elicit enhanced intestinal secretion and transit. Eur J Pharmacol 2010;649:328-335.
111. Eutamene H, Bradesi S, Larauche M, et al. Guanylate cyclase $\mathrm{C}$-mediated antinociceptive effects of linaclotide in rodent models of visceral pain. Neurogastroenterol Motil. 2010;22(3):312-e84.

112. Castro J, Harrington AM, Hughes PA, et al. Linaclotide inhibits colonic nociceptors and relieves abdominal pain via guanylate cyclase- $\mathrm{C}$ and extracellular cyclic guanosine 3',5'-monophosphate. Gastroenterology. 2013;145:1334-1346.

113. European Medicines Agency. Committee for Medicinal Products for Human Use (CHMP) assessment report: Constella, 2012. Available from: http://www.ema.europa.eu/docs/en_GB/document_library/ EPAR_-_Public_assessment_report/human/002490/WC500135624 pdf. Accessed December 23, 2012.

114. Chey WD, Lembo AJ, Lavins BJ, et al. Linaclotide for irritable bowel syndrome with constipation: a 26-week, randomized, double-blind, placebo controlled trial to evaluate efficacy and safety. Am J Gastroenterol. 2012;107:1702-1712.

115. Rao S, Lembo AJ, Shiff SJ, et al. A 12- week, randomized, controlled trial with a 4-week randomized withdrawal period to evaluate the efficacy and safety of linaclotide in irritable bowel syndrome with constipation. Am J Gastroenterol. 2012;107:1714-1724.

116. Quigley EM, Tack J, Chey WD, et al. Randomised clinical trials: linaclotide phase 3 studies in IBS-C - a prespecified further analysis based on European Medicines Agency-specified endpoints. Aliment Pharmacol Ther. 2013;37:49-61.

117. Ford AC, Quigley EM, Lacy BE, Lembo AJ, Saito YA, Schiller LR et al. Effect of antidepressant and psychological therapies, including hypnotherapy, in irritable bowel syndrome: systemic review and meta-analysis. Am J Gastroenterol. 2014;109(9):1350-1365.
Therapeutics and Clinical Risk Management

\section{Publish your work in this journal}

Therapeutics and Clinical Risk Management is an international, peerreviewed journal of clinical therapeutics and risk management, focusing on concise rapid reporting of clinical studies in all therapeutic areas, outcomes, safety, and programs for the effective, safe, and sustained use of medicines. This journal is indexed on PubMed Central, CAS,

\section{Dovepress}

EMBase, Scopus and the Elsevier Bibliographic databases. The manuscript management system is completely online and includes a very quick and fair peer-review system, which is all easy to use. Visit http://www.dovepress.com/testimonials.php to read real quotes from published authors.

Submit your manuscript here: http://www.dovepress.com/therapeutics-and-clinical-risk-management-journal 